\title{
Dialectical Methodology of the Praxis of Biology
}

\section{Bart Gremmen $^{1}$}

Accepted: 11 December 2020 / Published online: 30 March 2021

(c) The Author(s) 2021

\begin{abstract}
Zwart uses Hegel's dialectical method to develop a dialectical methodology for assessing biology as technoscience during the Anthropocene. In this paper I will evaluate this use of Hegelian dialectics in biology. I will first elaborate the meaning of Hegel's method of "Dialectics". This helps me to evaluate Zwart's dialectical scientific methodology from the perspective of Hegel's method of "Dialectics" and to evaluate Zwart's dialectical scientific methodology from the perspective of the praxis of biology. Finally, I will oppose Zwart's claim that the synthetic cell is an appropriate case study to demonstrate the relevance of dialectics for understanding contemporary biological research.
\end{abstract}

Keywords Ddialectical method $\cdot$ Biology $\cdot$ Hegel $\cdot$ Synthetic cell $\cdot$ Technoscience

\section{Philosophical Starting Point}

Science may be studied from several disciplinary backgrounds: history, philosophy, and social science. I totally agree with Zwart that to practice philosophy under current (anthropocenic) conditions, philosophers should know their proper place and position vis-à-vis other research fields. Studying science from a philosophical background is my philosophical starting point and I define it as the critical, systematic reflection on implicit and explicit assumptions about what we do. Like Zwart, I am in favour of an empirical way of doing philosophy in the life sciences. We do philosophy in the life sciences as embedded philosophers, discussing life sciences from within (Gremmen 2007). Starting from case material and concrete actual developments, philosophical concepts are used as flexible tools that can be adapted to specific contexts.

Zwart claims that he develops a dialectical methodology as a philosophical tool for assessing technoscience during the Anthropocene. This is a fairly general claim, but it isn't just a dialectical methodology, it is also a Hegelian one. Zwart uses the synthetic cell as a case study to demonstrate the relevance of dialectics for understanding contemporary

This comment refers to the article available at https://doi.org/10.1007/s10699-020-09738-1.

Bart Gremmen

bart.gremmen@wur.nl

1 Philosophy Group, Wageningen University, Wageningen, Netherlands 
research. He considers the synthetic cell project as a concrete exemplification of life under anthropocenic conditions. This leads to the following four questions:

1. What do we mean by Hegel's method of "Dialectics"?

2. Is dialectical scientific methodology adequate from the perspective of Hegel's method of "Dialectics"?

3. Is dialectical scientific methodology adequate from the perspective of the praxis of biology?

4. Is the synthetic cell an appropriate case study to demonstrate the relevance of dialectics for understanding contemporary biological research?

\section{Hegel's Dialectical method}

Zwart uses Hegel's dialectical method to develop a dialectical methodology for assessing technoscience during the Anthropocene. What do we mean by Hegel's method of "Dialectics"? Commentators unanimously describe it as a dynamical method that leads to a linear evolution or development from less sophisticated definitions or views to more sophisticated ones later (Maybee 2016). The source of this dynamics is a sort of contradictory process between three sides. These sides are moments of every logical concept. The first moment, understanding, is the moment of fixity, in which concepts or forms have a seemingly stable definition (Maybee 2016). The second moment, the dialectical moment or negatively rational moment, is the moment of instability. In this moment, a one-sidedness or restrictedness in the concept from the first moment becomes visible, and the concept that was stable in the first moment passes into its opposite (Maybee 2016). Hegel describes this process, from moment A to moment B, as a process of "self-sublation" (translation of Selbst-aufhebung). It has a double meaning: it means both to cancel (or negate) and to preserve at the same time. The first moment sublates itself because its one-sidedness destabilizes its definition and leads it to pass into its opposite in the second moment. The third moment, the "speculative" or "positively rational" moment, grasps the unity of the opposition between the definitions in the first- and the second moment. This dialectical process drives to the "Absolute": the final, and completely allencompassing concept in the relevant subject matter under discussion (Maybee 2016).

Hegel's dialectical method is about the dynamics of concepts. The nature of the earlier determinations drives the movement to new determinations by necessity, and thus an inward process without the need for some new idea to show up from the outside. From a methodological point of view, applying this dialectical method to science is to show the dynamics of scientific concepts in three moments. This means that scientists have to:

a. Describe the seemingly stable definition in the first moment;

b. Describe the one-sidedness or restrictedness in the second moment;

c. Grasp the unity of the opposition between the first two moments in the third moment.

In the next paragraph I will use these three steps to evaluate the adequacy of Zwart's dialectical scientific methodology from the perspective of Hegel's method of "Dialectics". 


\section{Dialectical Scientific Methodology}

Zwart describes the concept of life in moment A as something universal, integral and whole. A seemingly stable definition or determination of the concept of life in moment A is absent. He only claims that life in moment A is understood and described in a general way, in universal terms. The content of the concept in moment A is missing. Also he doesn't describe a one-sidedness or restrictedness in the determination from the moment of understanding the concept of universal life. Later in his paper Zwart describes that in moment A natural entities appear "... as they present themselves to us, as natural phenomena observed by us, whose integrity is respected by us" (This is a methodological remark preparing us for what happens in moment B: “... in order to understand something, this entity must be dissected and taken apart. Pushed to its extreme, this means completely destroying it. Analysis (Zerlegung in German) is a negative and inherently violent endeavour." This means that also in moment $\mathrm{B}$, where there is a focus on particular processes and components, there is no development of concepts, only the scientific step to analyse (take apart) the natural phenomena observed in moment B. Finally, according to Zwart in moment E the concrete synthetic cell represents the concrete realisation of the inevitable turn towards holism. He interprets this as a scientific step to reconstruct and re-converge. Like in the other two moments, there is no dialectical method of the development of concepts in moment E.

Zwart summarizes his dialectic methodology by the evolution of technoscience in general: "Dialectically speaking, this is how technoscience evolves as a praxis, involving a series of elucidating experiences: from respectful observation via disruptive analysis up to technoscientific individuation" This is a three-step dialectical methodology of science and not a dialectic method of concept development. However, Zwart equates his dialectical methodology in biology with the development of our idea of life: "These three moments (A $>$ B > E) represent the dialectical unfolding, starting from life as something universal, integral and whole (A), via the focus on particular processes and components (B), until individuation is regained on a higher level of comprehension, but now in the form of something very concrete: a metabolic and self-replicating synthetic cell in a test-tube (E)" This means that the three steps of biological technoscience are the development from something universal, to processes and components, to something very concrete. Because Zwart doesn't use the dialectical method of the development of concepts, he only develops a dialectical scientific methodology which is only loosely connected to a dialectic method of conceptual development. In the next paragraph I will evaluate Zwart's dialectical scientific methodology from the perspective of the praxis of biology.

\section{Three Dialectical Methodological Steps in the Praxis of Biology}

The first step of Zwart's scientific methodology is respectful observation of natural phenomena as they appear to us. To illustrate this he uses the example of technoscience aiming to understand the functioning of a tree. "During the first moment $\left(\mathrm{M}_{1}\right)$ we discern the tree as it presents itself to us, as a natural phenomenon: a Gestalt in a natural Umwelt, clad in natural daylight" Although I don't want to deny the possibility of trying to understand the tree as it presents itself to us, I wonder whether this is a scientific step. In my view Zwart's description of understanding the tree as it presents itself seems to belong to the field of phenomenology and not to biology. Is there a field in biology which studies life as 
something universal? Or may we re-interpret Zwart's) first step as another way to describe the plausible claim that a scientific field often starts with a theoretical phase?

The second step is analytic and reductionist. In order to understand the tree, it must be dissected and taken apart. To study it, life first of all has to be negated in a laboratory setting. Zwart concludes that this negativity is an inherent feature of science. However, is scientific analysis always a negative and inherently violent endeavour? I think that the experimental work of Mendel shows that it is possible to focus on biological processes and components without taken the plants apart. From 1856 to 1863 he concentrated on pairs of observable characters, such as color and form of the peas, of Pisum sativum (the garden pea) (Hartl and Orel 1992). Mendel studied the statistical laws governing the pattern of their re-appearance in the off-spring. Using special techniques of artificial pollination Mendel found that when two plants were crossed, the ratio of characters in the resulting generations could be expected to have been 1:1. However, he discovered that one character (dominant) appeared three times as frequently as another (recessive) (Hartl and Orel 1992). Although Mendel worked in a garden laboratory, he didn't dissect or violate his plants. He respected his plants and took great care not to damage them. This means that the second step is experimental but not necessarily negative.

The third step is about the turn towards holism by taking the scientific step to reconstruct and re-converge. According to Zwart this negates the negativity of technoscience via a concrete countervailing intervention. In my view synthesis, as a holistic methodology, and analysis belong together. It is all a matter of level. For example, on the level of the genome the sequencing data allow biologists to synthesise these data into a map of the genome. To define holism as reconstruction and convergence leads to a bio-engineering approach to biology. In the next paragraph I will evaluate Zwart's claim that the synthetic cell is an appropriate case study to demonstrate the relevance of dialectics for understanding contemporary biological research.

\section{From the Synthetic Cell to Systems Biology}

Zwart uses the synthetic cell as a case study to demonstrate the relevance of dialectics for understanding contemporary research. He claims that after the past twelve decades of dissolving living cells into their basic molecular and informational components, now it is time for a holistic turn, putting all these components together again. According to Zwart the synthetic cell project represents the inevitable transition, already envisioned by Hegel, from chemistry (unsustainable processes) to biology (self-sustainable processes). In his view this summarises all partial scientific experiences since the onset of contemporary life sciences research around the year 1900. In my view this is not an adequate historical picture of biology. I will illustrate this by the field of origin-of-life research.

Darwin already suggested that life arose from a 'warm little pond'. This begged the question of where the building blocks for life would have come from (Hyman and Brangwynne 2012). In 1924 Oparin argued that conditions on early Earth nurtured the synthesis of amino acids and their assembly into protocells. Oparin's book The Origin of Life (1938) describes the Earth's early atmosphere as a strongly reducing environment, rich in methane, water and ammonia. He posited that, with time and a supply of energy such as lightning or geothermal activity, these simple components would form the complex building blocks of life. Oparin's work made it possible to study the abiotic synthesis of organic biomolecules under prebiotic conditions. In 1952 Miller and Harold Urey tested Oparin's hypothesis 
by sending a continuous electric current through a glass vial containing water, hydrogen, methane and ammonia (Hyman and Brangwynne 2012). A substantial amount of the carbon had been converted into complex macromolecules, including many amino acids. This 'Miller-Urey' experiment not only confirmed the significance of Oparin's ideas, but transformed origins-of-life research from a largely theoretical to an experimental science and an explosion of data and ideas has blossomed in the decades that have followed (Hyman and Brangwynne 2012). The origin-of-life case also illustrates that scientists started this holistic field a long time before research on the synthetic cell. Also systems biology started much earlier as a theoretical field.

\section{Conclusion}

Around the turn of the 21th century, systems biology emerged. To facilitate many experimental biologists in this field, Yuri Lazebnik (2002) published a thought-provoking article about the importance of approaching complex biological circuits with an engineering perspective opposed to classical biological reductionism. He illustrated this by comparing the attempts of a biologist to repair a broken Russian transistor radio with the work of a trained electro-technical engineer. His suggestion was to develop a simple, quantitative language that experimental scientists could use to introduce themselves to formal descriptions of biological processes. Although such a language is still lacking, the switch from reductionist biology to bio-engineering seems to resonate positively with the ideas of Zwart

However, a closer look at the Lazebniks (2002) paper shows another picture. From his mentor he learned how his own field of apoptosis (a form of programmed cell death, or "cellular suicide") developed in four stages. At the first stage, a small number of scientists would somewhat leisurely discuss a problem that would appear esoteric to others. At this stage the understanding of the problem increases slowly, and scientists are generally nice to each other. Then, the second stage "...starts with an unexpected observation that makes many scientists realize that the previously mysterious process can be dissected with available tools. At once, the field is converted into a Klondike gold rush with all the characteristic dynamics, mentality, and morals. ... The resulting rapid expansion of the field increases the understanding of the biological process accordingly and results in a [third] phase of crystal clear models that often explain everything" (Lazebnik 2002: 179). This leads to the fourth stage at which models that seemed so complete, fall apart, and is characterized by a sense of frustration at the complexity of the process. The intensity of research remains unabated for a while, resulting in thousands of publications, many of which are contradictory or largely descriptive. "This [fourth] stage can be summarized by the paradox that the more facts we learn the less we understand the process we study" (Lazebnik 2002: 179).

In Zwart's paper I recognize more or less the first three stages in the development of a biological research field: a first theoretical stage, a second experimental stage and a third holistic stage. Instead of using the complex philosophy of Hegel to develop a scientific methodology, I propose to focus on the practice of science (Gremmen 2002). This offers the opportunity to address scientific concepts and comportment in specific sites and circumstances without attempting to address science as a vacuous generality relying on a "truly scientific" methodology (Galison 2008). 
Open Access This article is licensed under a Creative Commons Attribution 4.0 International License, which permits use, sharing, adaptation, distribution and reproduction in any medium or format, as long as you give appropriate credit to the original author(s) and the source, provide a link to the Creative Commons licence, and indicate if changes were made. The images or other third party material in this article are included in the article's Creative Commons licence, unless indicated otherwise in a credit line to the material. If material is not included in the article's Creative Commons licence and your intended use is not permitted by statutory regulation or exceeds the permitted use, you will need to obtain permission directly from the copyright holder. To view a copy of this licence, visit http://creativecommons.org/licenses/by/4.0/.

\section{References}

Galison, P. (2008). Ten problems in history and philosophy of science. ISIS, 99(1), 111-112. https://doi.org/ $10.1086 / 587536$.

Gremmen, B. (2002). Methodological pragmatism. In J. Keulartz (Ed.), Pragmatic ethics and technology. Dordrecht: Kluwer.

Gremmen, H. G. J. (2007). De zwakste schakel: over maatschappelijk verantwoorde genomics. Wageningen: Wageningen Universiteit.

Hartl, D. L., \& Orel, V. (1992). What did Gregor Mendel think he discovered? Genetics, 131(2), $245-253$.

Hyman, T., \& Brangwynne, C. (2012). In retrospect: the origin of life. Nature, 491, 524-525.

Lazebnik, Y. (2002). Can a biologist fix a radio?-or, what I learned while studying apoptosis. Cancer Cell, 2(3), 179-182.

Maybee, J. E. (2016). Hegel's dialectics. In E. N. Zalta (Ed.), Stanford encyclopedia of philosophy. Stanford: Stanford University.

Oparin, A. I. (1938). The Origin of life. New York: Macmillan.

Bart Gremmen is based at the Philosophy chair Group, known for applying ethical theory to life science domains with a strong focus on plant, animal and environmental ethics. His membership of the Plant Breeding group (2004-) and the Adaptation physiology group (2010-) and his collaboration with different Wageningen UR groups (environmental science; technology innovation; strategic communication) ensures a multi-disciplinary approach. Prof. Gremmen is a member of the environmental and ethics groups of the Netherlands Research School of Philosophy, and he has coordinated three large NWO genomics programs. He has been member of the management team of the 4TU Centre for Ethics of Technology and has established a strong international network of environmental and applied ethicists. He is also president of the International Society for the Hermeneutics of Science and chair of the Ethics working group of the European Association of Animals Scientists. 